Short Communication

\title{
An Electrochemical Benzylpenicillin Biosensor Based on $\beta$ - Lactamase and Fullerene Supported by A Bilayer Lipid Membrane
}

\author{
Yu Zhang*, Zhi Xia, Guofeng Gui, Gaoyu Zhao, Lifen Meng
}

College of Chemistry and Chemical Engineering, Guizhou University of Engineering Science, Bijie 551700, PR China

*E-mail: guaiguai3522@126.com

doi: $10.20964 / 2020.12 .66$

Received: 17 August 2020 / Accepted: 5 October 2020 / Published: 31 October 2020

\begin{abstract}
A novel biosensor with high sensitivity for the electrochemical detection of benzylpenicillin was successfully constructed by immobilizing $\beta$-Lactamase on a fullerene $\left(\mathrm{C}_{60}\right)$ supported bilayer lipid membrane $\left(\mathrm{C}_{60}-\mathrm{s}-\mathrm{BLM}\right)$ modified gold electrode $(\mathrm{GE})$. $\beta$-Lactamase was well immobilized on the electrode surface because of the good biocompatibility of the BLM. $\mathrm{C}_{60}$ was used as an electron transfer enhancer and an efficient immobilization matrix for the sensitivity enhancement. Transmission electron microscope (TEM) and cyclic voltammetry (CV) were used to characterize the surface morphology and the catalytic performance of the electrode, respectively. The results showed that the sensor had a good linearity in the range of $1.9-223.3 \mathrm{ng} / \mathrm{L}$ and a detection limit of $0.6 \mathrm{ng} / \mathrm{L}$.
\end{abstract}

Keywords: Benzylpenicillin; $\beta$-Lactamase; Fullerene; Bilayer lipid membrane; Biosensor

\section{FULL TEXT}

(C) 2020 The Authors. Published by ESG (www.electrochemsci.org). This article is an open access article distributed under the terms and conditions of the Creative Commons Attribution license (http://creativecommons.org/licenses/by/4.0/). 